\title{
Experimental Study on the Mechanical Properties and Seepage Characteristics of Red Sandstone with a Single Persistent Joint under Triaxial Compression
}

\author{
Wei Wang $\mathbb{D}^{1,2}$ Shifan Liu, ${ }^{1,2}$ Chong Shi $\mathbb{D}^{1,2}$ Shanxi Zheng, ${ }^{3}$ and Qizhi Zhu ${ }^{1,2}$ \\ ${ }^{1}$ Geotechnical Research Institute, Hohai University, Nanjing, Jiangsu 210098, China \\ ${ }^{2}$ Key Laboratory of Education for Geomechanics and Embankment Engineering, Hohai University, Nanjing, Jiangsu 210098, China \\ ${ }^{3}$ Nuclear Industry Huzhou Engineering Survey Institute Co. Ltd., Huzhou, Zhejiang 313000, China
}

Correspondence should be addressed to Wei Wang; wwang@hhu.edu.cn

Received 13 April 2021; Accepted 29 April 2021; Published 17 May 2021

Academic Editor: Feng Xiong

Copyright (c) 2021 Wei Wang et al. This is an open access article distributed under the Creative Commons Attribution License, which permits unrestricted use, distribution, and reproduction in any medium, provided the original work is properly cited.

\begin{abstract}
In this research, the conventional triaxial compression experiments for intact red sandstone specimens and the specimens with a single persistent joint at different inclination angles, i.e., $0^{\circ}, 30^{\circ}, 45^{\circ}$, and $90^{\circ}$, were conducted at first. Based on the results of the conventional tests, the effects of the confining pressure and the joint inclination angle on the mechanical properties including deformation behavior and strength parameters were summarized and analyzed, respectively. We find that the strength and deformation of jointed red sandstone are enlarged due to the increment of confining pressure, and the mechanical parameters of specimens show a U-shaped development with the rise of the joint angle. Besides, to investigate the effects of the pore pressure on seepage characteristics of rocks with joint angles at $0^{\circ}, 45^{\circ}$, and $90^{\circ}$, a series of triaxial compression drainage tests on the jointed red sandstone were performed. The results show that the pore pressure has a weakening effect on the strength of jointed specimens, which can reduce the strengthening effect induced by confining pressure. Meanwhile, the tested specimens mostly present shear failure modes. As a result, the mechanical responses, seepage characteristics, and cracking modes in red sandstone containing a single persistent joint under triaxial compression are revealed.
\end{abstract}

\section{Introduction}

Rock mass, formed during a long hydrogeological history, is a kind of natural material with complicated internal microstructure, which generally consists of two components, namely, the intact rock and discontinuities. The discontinuities can be either persistent or nonpersistent and appear as various types including primary cracks, joints, weak surfaces, and faults. These discontinuities have a great effect on the determination of the mechanical behavior of rock materials [1-4], which can further lead to the failure along the natural joint surfaces in rock engineering and need to be well treated [5-7]. Meanwhile, seepage properties of jointed rocks have a significant influence on the stability of rock engineering. During the initiation and development of jointed rock mass, the seepage driven by surface water and groundwater is often encountered. For jointed rock mass, the existence of joints provides channels for water seepage, accelerates the seepage process, causes changes in the internal microstructure of the rock mass, and macroscopically affects its physical properties, which may eventually lead to failure [8]. Consequently, the research on the seepage-mechanical coupling mechanism for jointed rocks has great theoretical and engineering significance.

Experimental studies on mechanical properties and failure modes of rock and rock-like specimens with nonpersistent joints and preexisting cracks have been widely performed. Bobet and Einstein [9] investigated the fracture coalescence of rock-like materials containing double preexisting fractures arranged in different geometries under uniaxial and biaxial loading. Wong and Einstein [10] reported the mechanical and cracking behaviors in modeled gypsum and marble specimens containing a single open crack under uniaxial compression. Lee and Jeon [11] studied the crack 
initiation, propagation, and coalescence of preexisting open cracks or flaws in granite and gypsum specimens under uniaxial compression. The deformation and strength behavior of sandstone specimens containing double preexisting closed nonoverlapping flaws under triaxial compression were investigated by Huang et al. [12]. Yang and Huang [13] performed conventional triaxial compression experiments of granite specimens with one preexisting open fissure to study their strength, deformability, and failure characteristics. Furthermore, new techniques such as the posttest X-ray computed tomography scanning technique were used to reveal the fracture behaviors of the marble samples in [14].

Recently, theoretical, experimental, and numerical studies on the mechanical behavior of persistent jointed rocks have been reported. The existing empirical methods for estimating the uniaxial compression strength of persistent jointed rock masses are reviewed and evaluated by Zhang [15]. Serrano et al. [16] proposed a microscopic determination method for the shear strength of persistent rock discontinuities. Li et al. [17] carried out experimental studies to investigate the effect of the initial opening on both the normal and shear deformations of rock joints and then proposed a fractal constitutive model which represents the shear behavior of a large-scale rock with persistent joint [18]. Based on the experiments of jointed rocks, numerical studies were further carried out to analyze the failure behavior of a rock slope by Zhu et al. [19]. Li and Zhu [20] proposed a meshfree numerical method to model the damage evolution and failure characteristics of fractured rocks. Besides, some pioneering research studies focusing on the seepage characteristics of jointed rocks have been conducted. The effects of shear deformation and normal stress on mechanical and seepage behavior of fractured rocks were experimentally investigated by Chen et al. [21]. Yin et al. [22] analyzed the influence of shear processes on nonlinear flow behavior based on their testing results of the 3-dimensional fractured rock. Wang et al. [23] and Gong et al. [24] carried out experimental investigations on mechanical properties and failure modes of jointed rocks under hydrochemical conditions. Shin and Santamarina [25] proposed an implicit joint-continuum model for the coupled hydromechanical analysis of persistent fractured rock, while Li et al. [26] investigated the permeability evolution in discrete fracture networks during shear.

However, the main contributions in most of the above studies are mainly limited to a single aspect of mechanical properties or seepage characteristics of rocks. Therefore, to comprehensively study the triaxial mechanical properties and seepage characteristics of jointed rocks, in the present paper, the conventional triaxial tests on red sandstone with a single persistent joint are firstly conducted. Then, a series of triaxial compression drainage tests on the jointed red sandstone are performed and the results are analyzed. Finally, we summarize the findings and close the paper with potential perspectives.

\section{Experimental Methodology}

2.1. Specimen Preparation. To investigate the mechanical properties and seepage characteristics of rock with a single

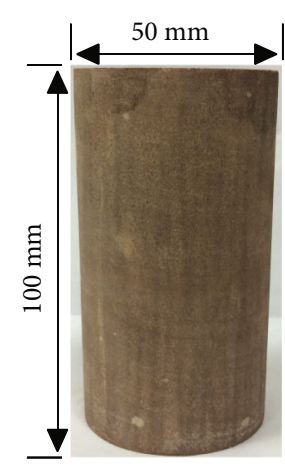

(a)

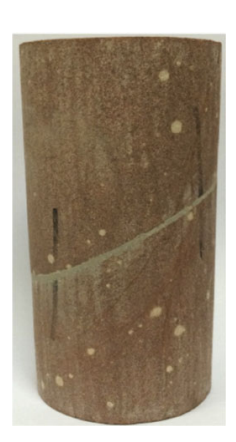

(b)

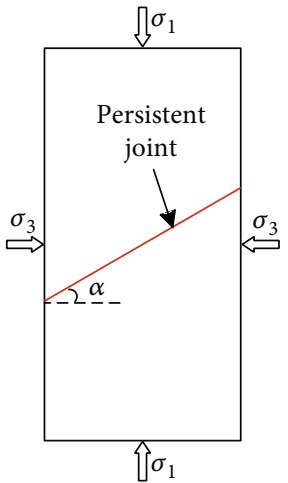

(c)
FIGURE 1: The geometry and types of red sandstone specimens: (a) the intact type of specimen with dimensioning, (b) the type of specimen with a single persistent joint (take $\alpha=30^{\circ}$ as an example), and (c) the schematic of the persistent joint in the specimen under triaxial compression condition, where $\sigma_{1}$ denotes the axial stress.

persistent joint under triaxial compression, red sandstone from a certain engineering rock mass in China was chosen as the experimental material for this research. The tested red sandstone is fine-grained and macroscopically homogeneous, with an average bulk density of about $2450 \mathrm{~kg} / \mathrm{m}^{3}$. A bridge-type infrared cutting machine was chosen to preliminary cut the rock mass into small suitable-sized cuboids. Then, the cuboids were processed into cylindrical specimens with $50 \mathrm{~mm}$ in diameter and $100 \mathrm{~mm}$ in height, according to the method suggested by the International Society for Rock Mechanics (ISRM) [27].

In the present research, intact specimens and four types of specimens with various joint inclination angles $\alpha$, i.e., $0^{\circ}$, $30^{\circ}, 45^{\circ}$, and $90^{\circ}$, were prepared for studying the effects of the inclination angle on the mechanical properties and failure modes of the red sandstone. The geometry and types of specimens are briefly depicted in Figure 1. The production procedure of the jointed specimens is described as follows: (1) by controlling the direction of the specimens and using the infrared cutting machine, the cylindrical intact specimens were cut into two parts with the desired joint inclination angles; (2) then, cement was used for filling the interface; based on the results from [9], cement could be regarded as a weak material which only provides cementation without affecting rock properties; (3) after 48 hours, the red sandstone can be well bonded by cement; and (4) after the surface of the filling part is polished, the jointed specimens are finally manufactured. The experiments of specimens were carried out under three confining pressures $\sigma_{3}$, i.e., 0,10 , and $20 \mathrm{MPa}$, in conventional triaxial tests, to investigate the effect of the confining pressure on the mechanical and cracking behavior. For the triaxial compression drainage tests, the pore pressure $p$ was set as $4 \mathrm{MPa}$ and $8 \mathrm{MPa}$. Detailed descriptions for red sandstone specimens in conventional triaxial tests with different joint inclination angles are listed in Table 1, while Table 2 shows the detailed geometry of red sandstone specimens in triaxial compression drainage tests. 
TABLE 1: The detailed geometry of red sandstone specimens in conventional triaxial tests.

\begin{tabular}{|c|c|c|c|c|}
\hline $\begin{array}{l}\text { Inclination } \\
\text { angles }\end{array}$ & Specimen label & $\begin{array}{c}D \\
(\mathrm{~mm})\end{array}$ & $\begin{array}{c}H \\
(\mathrm{~mm})\end{array}$ & $\begin{array}{c}\sigma_{3} \\
(\mathrm{MPa})\end{array}$ \\
\hline \multirow{3}{*}{ Intact } & SY-I-0 & 50.03 & 100.18 & 0 \\
\hline & SY-I-10 & 50.18 & 99.92 & 10 \\
\hline & SY-I-20 & 49.79 & 99.88 & 20 \\
\hline \multirow{3}{*}{$0^{\circ}$} & $S Y-0^{\circ}-0$ & 50.35 & 101.19 & 0 \\
\hline & $S Y-0^{\circ}-10$ & 50.38 & 101.29 & 10 \\
\hline & $S Y-0^{\circ}-20$ & 50.14 & 100.95 & 20 \\
\hline \multirow{3}{*}{$30^{\circ}$} & $S Y-30^{\circ}-0$ & 50.21 & 100.86 & 0 \\
\hline & SY $-30^{\circ}-10$ & 49.84 & 100.71 & 10 \\
\hline & SY $-30^{\circ}-20$ & 50.02 & 100.76 & 20 \\
\hline \multirow{3}{*}{$45^{\circ}$} & SY $-45^{\circ}-0$ & 49.78 & 100.80 & 0 \\
\hline & $S Y-45^{\circ}-10$ & 50.36 & 100.85 & 10 \\
\hline & SY $-45^{\circ}-20$ & 49.86 & 100.56 & 20 \\
\hline \multirow{3}{*}{$90^{\circ}$} & SY $-90^{\circ}-0$ & 50.25 & 100.05 & 0 \\
\hline & SY $-90^{\circ}-10$ & 49.89 & 100.02 & 10 \\
\hline & SY $-90^{\circ}-20$ & 49.86 & 100.05 & 20 \\
\hline
\end{tabular}

Note: $D$ : diameter; $H$ : height.

TABLE 2: The detailed geometry of red sandstone specimens in triaxial compression drainage tests.

\begin{tabular}{|c|c|c|c|c|c|}
\hline $\begin{array}{l}\text { Inclination } \\
\text { angles }\end{array}$ & $\begin{array}{l}\text { Specimen } \\
\text { label }\end{array}$ & $\begin{array}{c}D \\
(\mathrm{~mm})\end{array}$ & $\begin{array}{c}H \\
(\mathrm{~mm})\end{array}$ & $\begin{array}{c}\sigma_{3} \\
(\mathrm{MPa})\end{array}$ & $\begin{array}{c}p \\
(\mathrm{MPa})\end{array}$ \\
\hline \multirow{4}{*}{$0^{\circ}$} & SD- $0^{\circ}-10-4$ & 49.95 & 98.91 & 10 & 4 \\
\hline & SD- $0^{\circ}-10-8$ & 50.02 & 97.91 & 10 & 8 \\
\hline & $S D-0^{\circ}-20-4$ & 49.93 & 97.43 & 20 & 4 \\
\hline & SD- $0^{\circ}-20-8$ & 49.97 & 98.20 & 20 & 8 \\
\hline \multirow{4}{*}{$45^{\circ}$} & SD $-45^{\circ}-10-4$ & 50.10 & 96.64 & 10 & 4 \\
\hline & SD $-45^{\circ}-10-8$ & 50.05 & 99.15 & 10 & 8 \\
\hline & SD $-45^{\circ}-20-4$ & 50.28 & 97.30 & 20 & 4 \\
\hline & SD $-45^{\circ}-20-8$ & 50.03 & 97.86 & 20 & 8 \\
\hline \multirow{4}{*}{$90^{\circ}$} & SD $-90^{\circ}-10-4$ & 51.10 & 99.89 & 10 & 4 \\
\hline & SD $-90^{\circ}-10-8$ & 50.83 & 100.02 & 10 & 8 \\
\hline & SD- $90^{\circ}-20-4$ & 51.21 & 99.84 & 20 & 4 \\
\hline & SD- $90^{\circ}-20-8$ & 51.11 & 100.21 & 20 & 8 \\
\hline
\end{tabular}

2.2. Testing Apparatus and Procedure. All the triaxial compression experiments were performed on the rock automatic servo-controlled triaxial testing machine (see Figure 2). The equipment includes a triaxial pressure chamber, a loading system, a constant-stability pressure device, an ultrasonic system, a hydraulic pressure system with a pressure transfer device, a pneumatic system, and an automatic data collection system. The three high-pressure pumps in the loading system can control the steady loading and automatic compensation of deviatoric pressure, confining pressure, and water pressure. This equipment is able to perform tests including conventional uniaxial tests, triaxial tests, rheological tests, triaxial drainage tests, undrained tests, hydraulic and pneumatic penetration tests, and ultrasonic tests. The strain

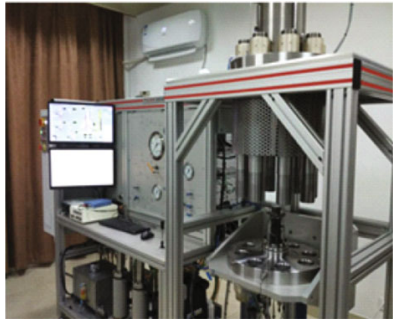

(a)

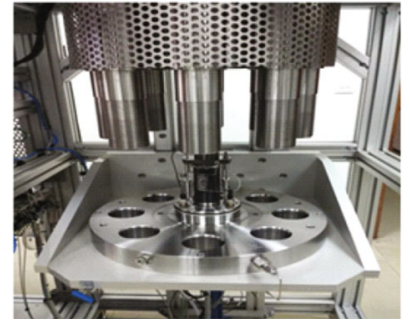

(b)
FIgURe 2: Photographs of the rock automatic servo-controlled triaxial testing machine: (a) the overall view of the equipment and (b) the triaxial pressure chamber.

measurement system consists of linear variable differential transformer (LVDT) for measuring the axial strain and circumferential strain measurement ring for measuring the circumferential strain.

To reduce the influence of temperature on the test results, the temperature in the laboratory is strictly controlled at $20 \pm 0.5^{\circ} \mathrm{C}$. For the conventional triaxial compression experiment, the detailed procedures are listed as follows: (1) first, the confining pressure was applied to the specimen at a constant loading rate of $0.1 \mathrm{MPa} / \mathrm{s}$ to ensure that the specimen was under the uniform hydrostatic stress condition; and (2) then, the deviatoric stress was imposed on the surface of the specimen at a constant displacement rate of $0.025 \mathrm{~mm} / \mathrm{min}$ until the specimen failed.

For the triaxial compression drainage tests, the jointed specimens were saturated before the tests. After the same procedure with step (1) in the conventional test, when the confining pressure was stable, the seepage pressure should be loaded, and it needs to be less than the confining pressure. The rock sample should be saturated until water flows out of the outlet. After the pore pressure reached the predetermined value, the servo-control method was adopted to keep the pore pressure stable. Then, the deviatoric stress was applied by a constant displacement rate of $0.025 \mathrm{~mm} / \mathrm{min}$ until the specimen failed. Meanwhile, during the process of all the tests, the automatic data collection system can record and digitize the test data in real time, which provides convenience for data analysis.

\section{Conventional Triaxial Test Results and Analysis}

3.1. Stress-Strain Curves. The axial deviatoric stress-strain curves of intact and jointed red sandstone under different confining pressures are shown in Figure 3. In accordance with Figure 3, for all specimens, a quasi-brittle mechanical behavior can be found and the overall phenomenon demonstrates that the slopes of the curves increase with the confining pressure $\sigma_{3}$. Likewise, the values of $\sigma_{\mathrm{c}}$ increase when $\sigma_{3}$ gets higher. Notably, the trends of curves of deviatoric stress $\left(\sigma_{1}-\sigma_{3}\right)$ versus the strain have (I) the nonlinear stage, (II) the elastic stage, (III) the stable crack growth stage, and (IV) the yielding stage before reaching the peak deviatoric stress $\sigma_{c}$. Thereafter, the axial stress drops sharply after the peak stress with a tiny increase of axial strain. The curves 


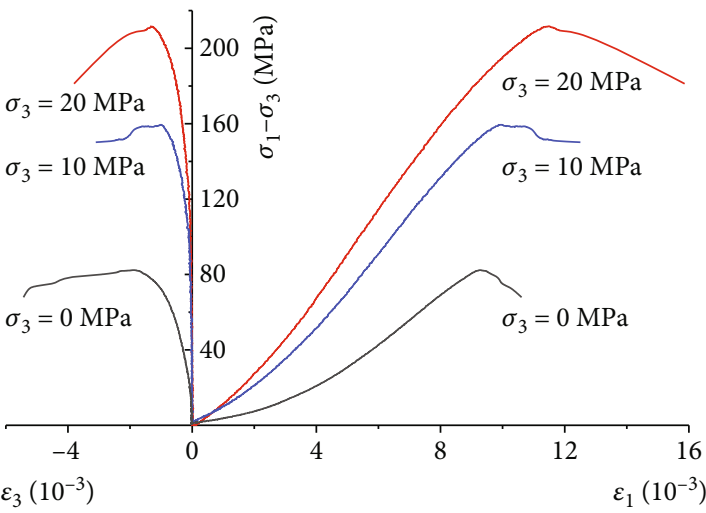

(a)

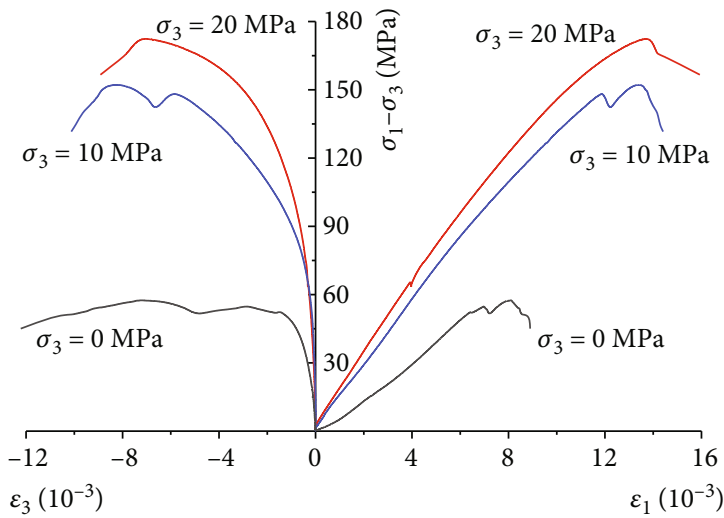

(c)

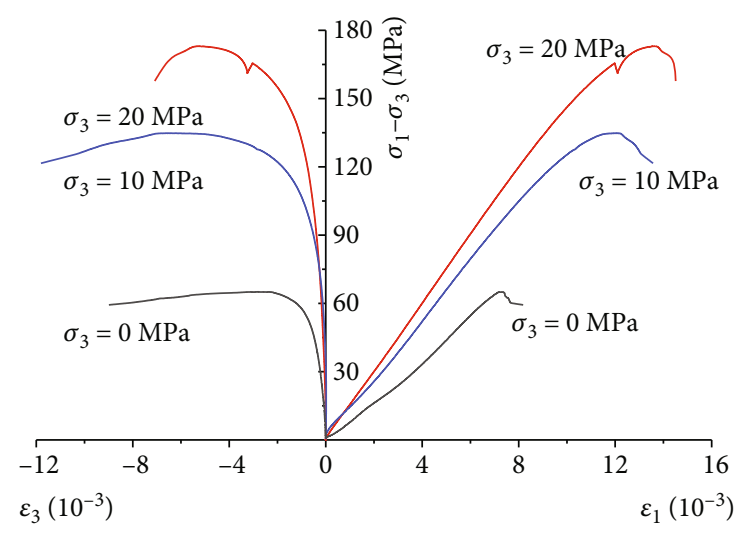

(b)

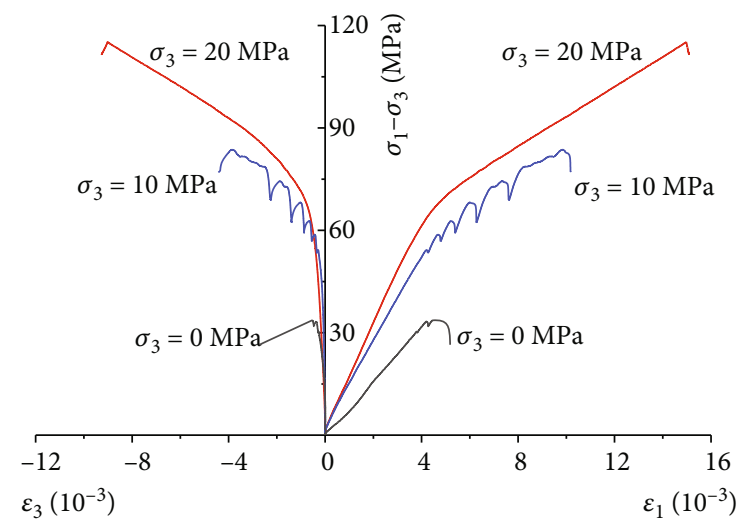

(d)

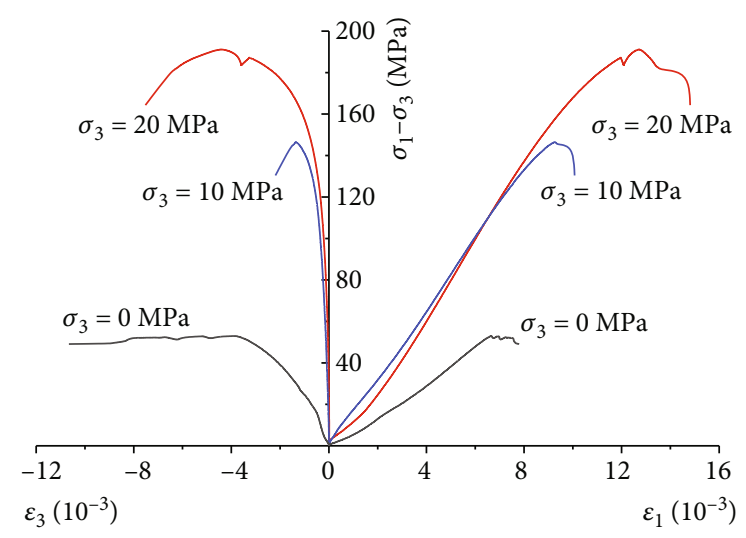

(e)

Figure 3: Axial deviatoric stress-strain curves of intact specimens and red sandstone containing a single persistent joint with various joint angles under different confining pressure: (a) intact specimens, (b) $\alpha=0^{\circ}$, (c) $\alpha=30^{\circ}$, (d) $\alpha=45^{\circ}$, and (e) $\alpha=90^{\circ}$.

may appear to be serration-type stress drops when near the point of peak strength (see Figure $3(\mathrm{~d})$ ), which results from the initiation and propagation of cracks inside the specimens. The location and numbers of the stress drops are closely related to the joint inclination angles. Moreover, the circumferential strains $\varepsilon_{3}$ have an infinitesimal value at the initial loading condition, which are far smaller than their corresponding axial strain $\varepsilon_{1}$. More detailed analyses of deformation and strength characteristics are explained in the following sections.
3.2. Analysis of the Volumetric Deformation Characteristics. Under triaxial compression conditions, the total volumetric strain $\varepsilon_{\mathrm{v}}$ is calculated as

$$
\varepsilon_{\mathrm{v}}=\varepsilon_{1}+2 \varepsilon_{3}
$$

which can be considered as the composition of two portions: one is the volumetric strain induced by the elastic deformation, namely, the elastic volumetric strain $\varepsilon_{\mathrm{v}}^{\mathrm{e}}$, and the other is the portion attributed to the crack development, which is 
called the crack-induced volumetric strain and denoted as $\varepsilon_{\mathrm{v}}^{\mathrm{c}}$. Based on Hooke's law, $\varepsilon_{\mathrm{v}}^{\mathrm{e}}$ is given by

$$
\varepsilon_{\mathrm{v}}^{\mathrm{e}}=\frac{(1-2 \mu)\left(\sigma_{1}+2 \sigma_{3}\right)}{E}
$$

where $E$ is the elastic modulus and $\mu$ is Poisson's ratio of the specimen. Following the approximation proposed by Li et al. [28], $\varepsilon_{\mathrm{v}}^{\mathrm{c}}$ can be defined as

$$
\varepsilon_{\mathrm{v}}^{\mathrm{c}}:=\varepsilon_{\mathrm{v}}-\varepsilon_{\mathrm{v}}^{\mathrm{e}}
$$

Figure 4 presents the typical relationship between $\left(\sigma_{1}-\right.$ $\left.\sigma_{3}\right), \varepsilon_{\mathrm{v}}, \varepsilon_{\mathrm{v}}^{\mathrm{c}}$, and $\varepsilon_{1}$ of the jointed specimens under the confining pressure at $10 \mathrm{MPa}$. In Figure 4, four prepeak stages I-IV, i.e., stage I, the nonlinear stage owing to crack closure with a maximum at $\sigma_{c c}$; stage II, the elastic stage with a maximum at the crack initiation $\sigma_{\mathrm{ci}}$; stage III, the stable crack growth stage between $\sigma_{\mathrm{ci}}$ and the crack damage threshold $\sigma_{\mathrm{cd}}$; and stage IV, the yielding stage with the initiation of macroscopic failure of specimens before the peak point, and a postpeak stage $\mathrm{V}$ were distinctively described. Accordingly, the development of prepeak $\varepsilon_{\mathrm{v}}$ also shows four stages, i.e., the volumetric compaction stage, the linear volumetric growth stage, the volumetric dilation stage, and the volume rapid increasing stage, corresponding to the compression process of jointed rock specimens. At the compaction stage, the primary transverse crack perpendicular to the axial direction is compacted due to the initial loading, while $\varepsilon_{3}$ basically has no growth, and hence, the trend of the volumetric compaction is consistent with the change of $\varepsilon_{1}$. For the linear volumetric growth stage, $\varepsilon_{1}$ and $\varepsilon_{3}$ both grow linearly. The growth amplitude of $\varepsilon_{3}$ is less than that of $\varepsilon_{1}$, which is also reflected as a linear growth stage of $\varepsilon_{\mathrm{v}}$, correspondingly. When $\varepsilon_{3}$ begins to yield, the growth range of $\varepsilon_{3}$ increases obviously, while the growth range of $\varepsilon_{1}$ is relatively slow, and $\varepsilon_{\mathrm{v}}$ begins to present dilation behavior. When the specimen is close to failure, $\varepsilon_{3}$ increases sharply, while $\varepsilon_{1}$ grows less, and the growth of $\varepsilon_{\mathrm{v}}$ is consistent with the circumferential growth.

For the specimens with different joint inclination angles, some common characteristics from the curves of $\varepsilon_{\mathrm{v}}$ and $\varepsilon_{\mathrm{v}}^{\mathrm{c}}$ versus $\varepsilon_{1}$ can be obtained from Figure 4 . At stage II, $\varepsilon_{\mathrm{v}}^{\mathrm{c}}$ increases slowly, while $\varepsilon_{\mathrm{v}}$ exhibits a linear growth when $\varepsilon_{1}$ rises. At stage III, cracks initiate and develop stably, and hence the values of $\varepsilon_{\mathrm{v}}$ begins to increase slightly and $\varepsilon_{\mathrm{v}}^{\mathrm{c}}$ decreases linearly. At stage IV, both the curves of $\varepsilon_{\mathrm{v}}$ and $\varepsilon_{\mathrm{v}}^{\mathrm{c}}$ versus $\varepsilon_{1}$ display a sharp reduction, which implies that the deformation state of specimens turns contraction into dilation and the material begins to perform macroscale failure. In addition, at stage II, it can be found that the slopes of the $\varepsilon_{\mathrm{v}}^{\mathrm{c}}$ versus $\varepsilon_{1}$ curves for joint angles of $45^{\circ}$ and $90^{\circ}$ are larger than those of $0^{\circ}$ and $30^{\circ}$, and the jointed specimens with the dip angles of $45^{\circ}$ and $90^{\circ}$ present more clearly quasi-elastic behavior, which indicates that the joint angle has a certain influence on $\varepsilon_{\mathrm{v}}^{\mathrm{c}}$.

\subsection{Analysis of Strength Characteristics}

3.3.1. The Peak Strength. As illustrated above, Figures 3 and 4 have shown the characteristics of the critical stress points; the crack initiation stress $\sigma_{\mathrm{ci}}$ and the crack damage threshold $\sigma_{\mathrm{cd}}$ are clearly marked in the curves. Table 3 summarizes the values of $\sigma_{\mathrm{cd}}$ and $\sigma_{\mathrm{ci}}$ and their ratios to $\sigma_{\mathrm{c}}$ of intact specimens and the persistent jointed specimens with different joint angles. It is obvious that $\sigma_{\mathrm{c}}$ rises with the increment of $\sigma_{3}$. A similar behavior can be found in $\sigma_{\text {cd }}$ and $\sigma_{\text {ci }}$ with $\sigma_{3}$. The jointed specimens always have a smaller crack initiation strength and damage threshold than the intact specimens due to the degradation effects of the preexisting joint on the strength. Another significant phenomenon is that, when the joint angle is equal to $45^{\circ}$, the preexisting joint lies on the theoretical weakest slippage surface, which leads to the smallest $\sigma_{\mathrm{cd}}$ and $\sigma_{\mathrm{ci}}$. In accordance with the experimental results, the values of $\sigma_{c d} / \sigma_{c}$ of intact specimens are approximate to 1 , whereas the ratios of jointed specimens range from 0.581 to 0.995. This might reveal that the intact specimens ruptured quickly after the crack damage threshold was reached. Besides, the ratios, $\sigma_{\mathrm{ci}} / \sigma_{\mathrm{c}}$, of intact specimens and jointed specimens lie between 0.428 and 0.835 , which are independent of $\sigma_{3}$ and show no specific trends when $\sigma_{3}$ rises.

3.3.2. Analysis of Strength Parameters. This study adopted the linear Mohr-Coulomb (M-C) criterion to fit the peak strength and the crack damage strength with confining pressure. The linear $\mathrm{M}-\mathrm{C}$ criterion can be given as follows:

$$
\left\{\begin{array}{l}
\sigma_{1}=M \sigma_{3}+N \\
\varphi=\arcsin \left(\frac{M-1}{M+1}\right), \\
c=N \frac{1-\sin \varphi}{2 \cos \varphi},
\end{array}\right.
$$

where $M$ and $N$ are two material parameters. The parameters $c$ and $\varphi$ are the cohesion and the internal friction angle of rocks, respectively.

Figure 5 presents the fitting results of the peak strength and crack damage threshold of intact and jointed specimens versus confining pressure. Besides, Tables 4 and 5 list the fitting parameters corresponding to the peak strength and crack damage threshold, respectively. It is clear that the peak strength and crack damage threshold exerted a good linear behavior with the increase of confining pressure for the specimens.

For intact specimens, the cohesion $c$ and the friction angle $\varphi$ in terms of the peak strength are $15.83 \mathrm{MPa}$ and $49.81^{\circ}$, respectively, which are approximately equal to $c_{\mathrm{d}}$ and $\varphi_{\mathrm{d}}$ in terms of the crack damage threshold, i.e., 15.43 $\mathrm{MPa}$ and $49.75^{\circ}$, respectively. However, for the jointed specimen, $c$ ranges from $8.36 \mathrm{MPa}$ to $13.89 \mathrm{MPa}$, whereas the value of $c_{\mathrm{d}}$ lies between 9.97 MPa and 11.97 MPa. In comparison, the values of $c$ and $c_{\mathrm{d}}$ of jointed specimens are lower than those of intact specimens. Meanwhile, for the jointed specimen, $\varphi$ is approximately $41.94 \sim 50.85^{\circ}$, while $\varphi_{\mathrm{d}}$ lies between $30.41^{\circ}$ and $48.70^{\circ}$. It is clear that $\varphi$ and $\varphi_{\mathrm{d}}$ of jointed specimens are lower than those of intact red sandstone specimens expect for the values at $90^{\circ}$ angles (namely, showing a 

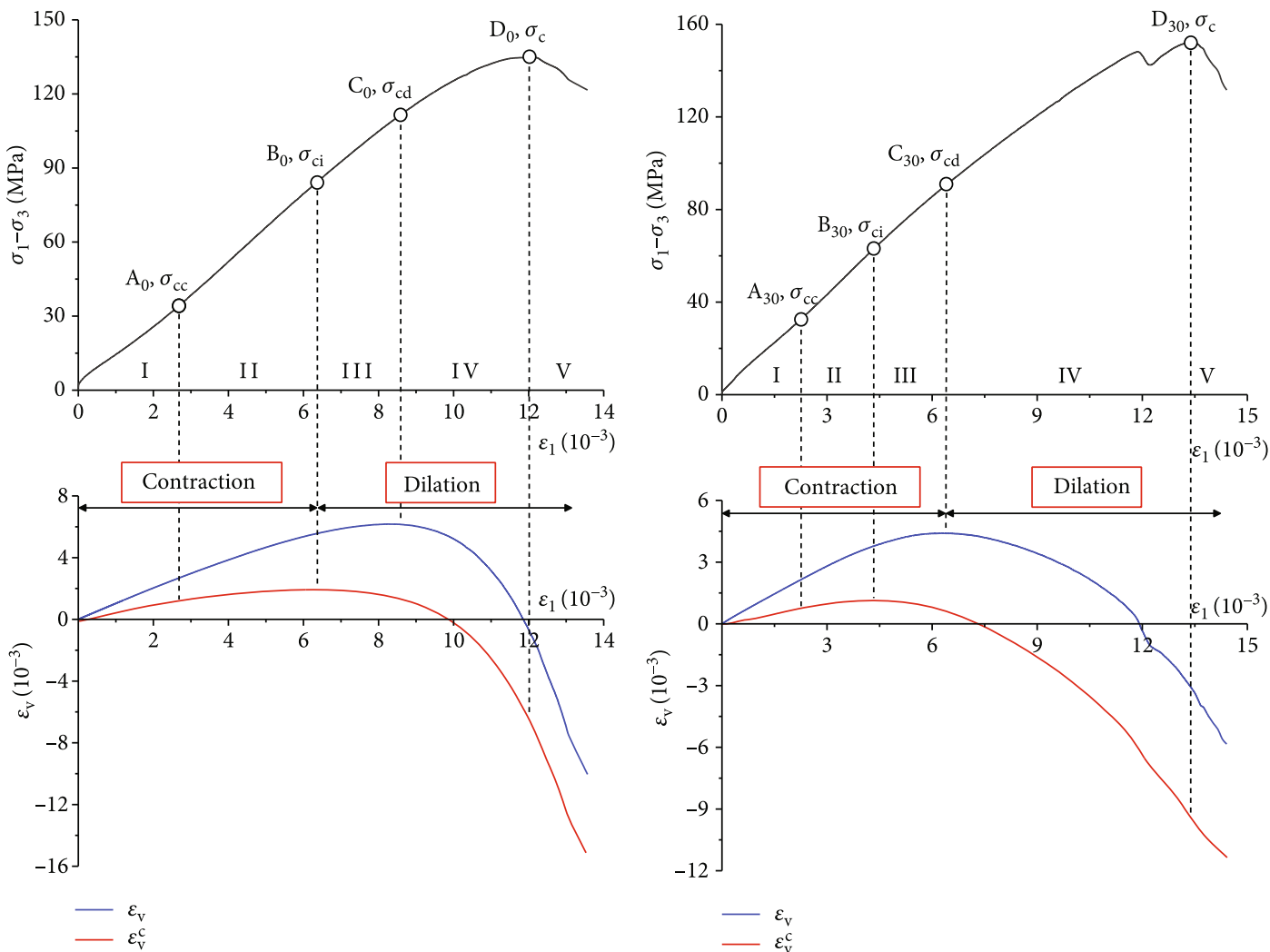

(a)
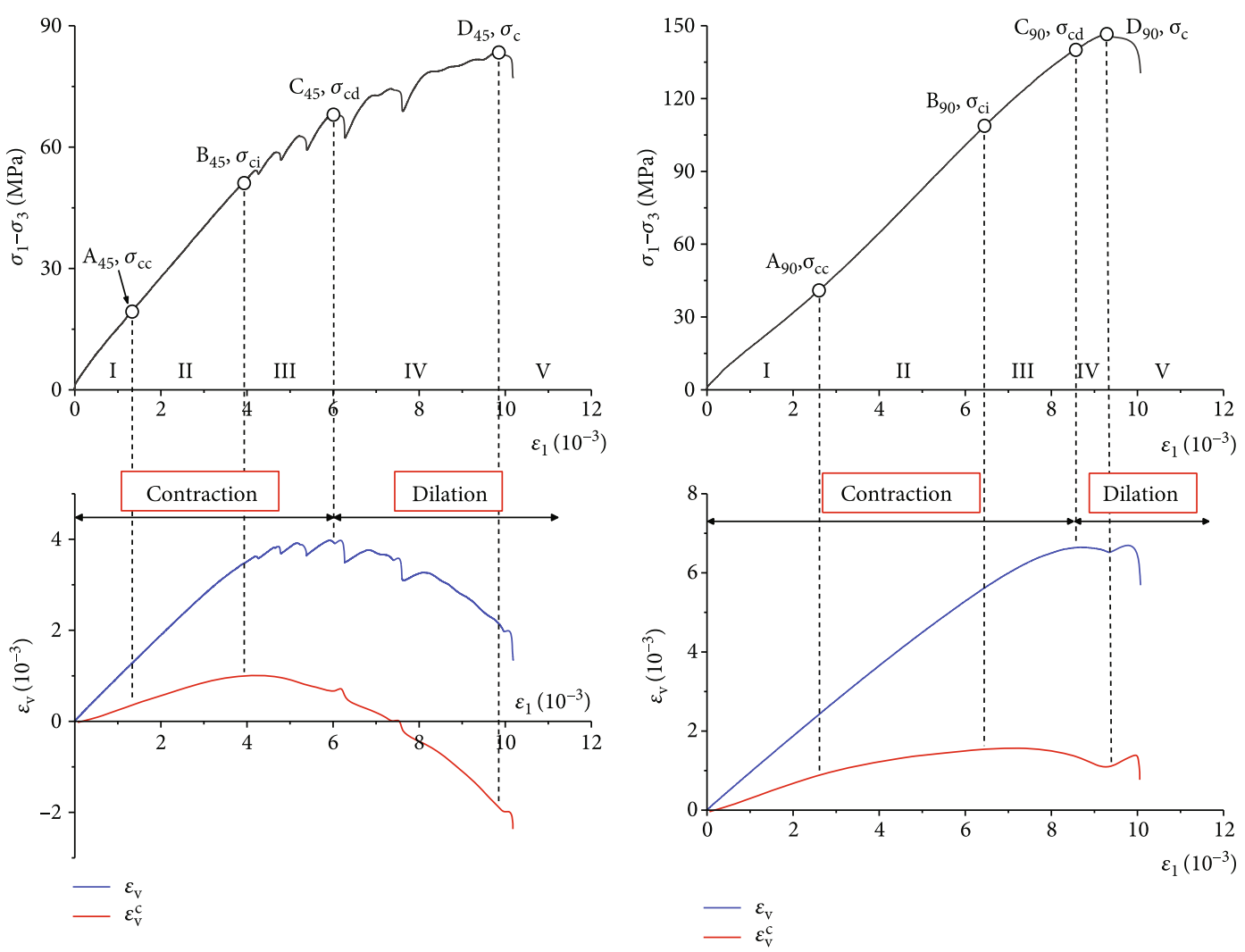

(c)

(d)

FIGURE 4: A typical evolution of the volumetric strain of red sandstone containing a persistent joint when the confining pressure is $10 \mathrm{MPa}$ : (a) $\alpha=0^{\circ}$, (b) $\alpha=30^{\circ}$, (c) $\alpha=45^{\circ}$, and (d) $\alpha=90^{\circ}$. 
TABLE 3: The strength and strength ratios of specimens in conventional triaxial compression tests.

\begin{tabular}{lcccccc}
\hline $\begin{array}{l}\text { Inclination } \\
\text { angles }\end{array}$ & $\begin{array}{c}\sigma_{3} \\
(\mathrm{MPa})\end{array}$ & $\begin{array}{c}\sigma_{\mathrm{c}} \\
(\mathrm{MPa})\end{array}$ & $\begin{array}{c}\sigma_{\mathrm{cd}} \\
(\mathrm{MPa})\end{array}$ & $\begin{array}{c}\sigma_{\mathrm{ci}} \\
(\mathrm{MPa})\end{array}$ & $\sigma_{\mathrm{cd}} / \sigma_{\mathrm{c}}$ & $\sigma_{\mathrm{ci}} / \sigma_{\mathrm{c}}$ \\
\hline \multirow{3}{*}{ Intact } & 0 & 82.35 & 79.22 & 39.78 & 0.962 & 0.483 \\
& 10 & 159.55 & 158.70 & 107.70 & 0.995 & 0.675 \\
& 20 & 211.78 & 208.20 & 176.90 & 0.983 & 0.835 \\
$0^{\circ}$ & 0 & 65.03 & 53.04 & 39.78 & 0.816 & 0.612 \\
& 10 & 134.83 & 107.35 & 84.66 & 0.796 & 0.628 \\
& 20 & 173.03 & 142.96 & 114.84 & 0.826 & 0.664 \\
$30^{\circ}$ & 0 & 57.49 & 44.37 & 27.35 & 0.772 & 0.476 \\
& 10 & 152.14 & 88.42 & 65.12 & 0.581 & 0.428 \\
& 20 & 172.37 & 127.28 & 80.41 & 0.738 & 0.466 \\
$45^{\circ}$ & 0 & 34.60 & 33.37 & 23.76 & 0.964 & 0.687 \\
& 10 & 83.67 & 67.83 & 50.98 & 0.811 & 0.609 \\
& 20 & 115.24 & 74.43 & 58.64 & 0.646 & 0.509 \\
$90^{\circ}$ & 0 & 52.94 & 38.81 & 24.33 & 0.733 & 0.460 \\
& 10 & 146.45 & 141.52 & 110.02 & 0.966 & 0.751 \\
& 20 & 191.14 & 159.62 & 129.78 & 0.835 & 0.679 \\
\hline
\end{tabular}

U-shaped trend), which is similar to the conclusion of the specimen containing nonpersistent joints [2].

\section{Triaxial Compression Drainage Test Results and Analysis}

In this section, triaxial compression drainage tests have been carried out on jointed red sandstone. The mechanical properties and seepage characteristics of specimens with different joint inclination angles are studied under the action of different confining pressures and pore pressures. The effects of the pore pressure and inclination angle on red sandstone hydromechanical behavior under triaxial conditions are compared and analyzed.

4.1. Analysis of Stress-Strain Curves. During triaxial compression drainage tests, the mechanical responses of jointed rock specimens will be affected by three factors, i.e., the joint inclination angle $\alpha$, the pore pressure $p$, and the confining pressure $\sigma_{3}$. In the present work, we focus on the effect of the joint inclination angle and the pore pressure on the rock's behavior. Combined with the results of compression tests under different levels of pore pressure and the obtained results in Section 3, the effects of various pore pressures on the characteristics of jointed specimens with the same joint angle and confining pressure are investigated, and the major parameters are listed in Table 6. The statistical results of stress-strain curves with different joint angles are illustrated in Figures 6-8.

Here, we first take the results of the inclination angle at $0^{\circ}$ as an example. It can be seen from Figure 6 that under the same $\sigma_{3}$, with the increase of pore pressure $p$, the peak strength and the peak strain of the specimens decrease gradually. When $\sigma_{3}$ is equal to $10 \mathrm{MPa}$, the corresponding peak values of $p$ at $4 \mathrm{MPa}$ and $8 \mathrm{MPa}$ are $113.22 \mathrm{MPa}$ and

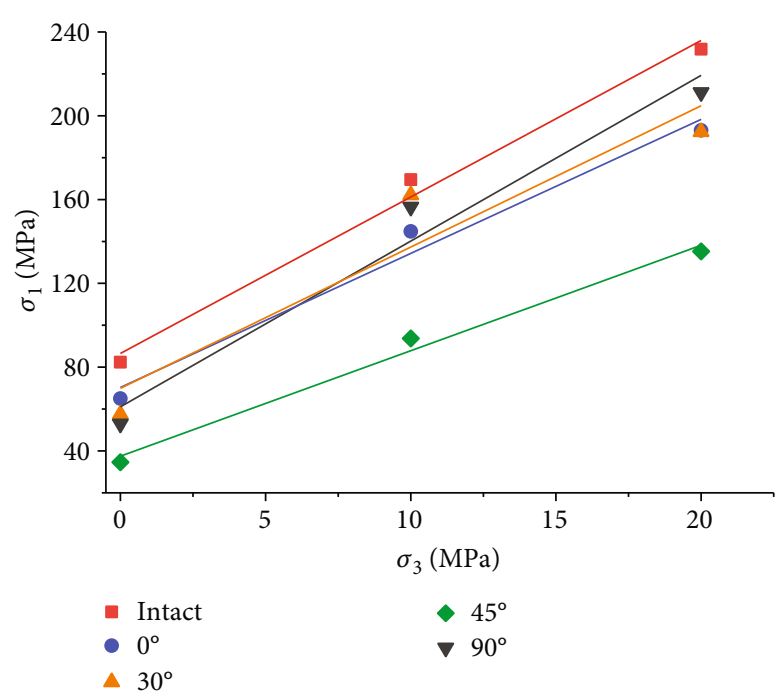

(a)

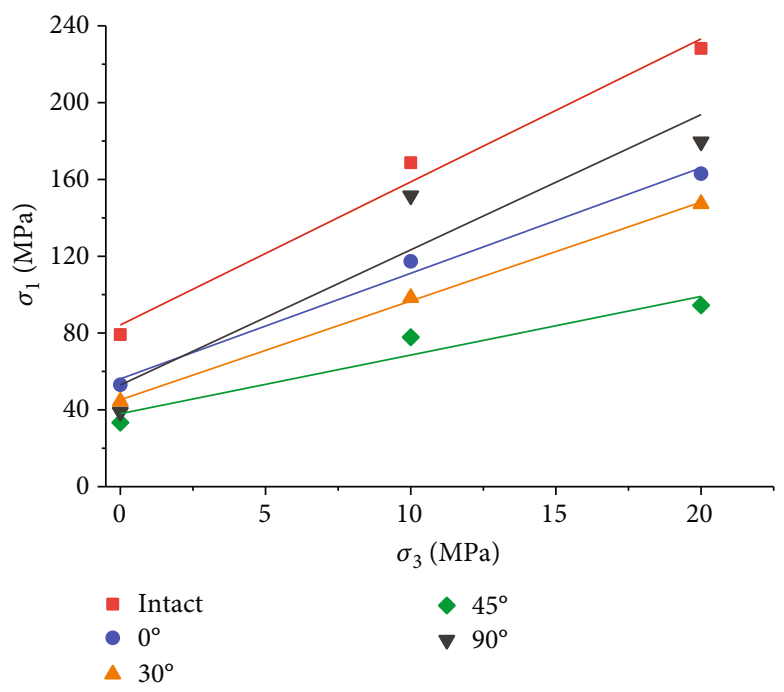

(b)

FIgURE 5: The fitting results using the $\mathrm{M}-\mathrm{C}$ criterion: (a) peak stress and (b) peak axial stress with respect to the crack damage.

TABle 4: Parameters of the peak strength corresponding to the linear M-C criterion.

\begin{tabular}{lccccc}
\hline Joint angles & $M$ & $N(\mathrm{MPa})$ & $c(\mathrm{MPa})$ & $\varphi\left(^{\circ}\right)$ & $R^{2}$ \\
\hline Intact & 7.47 & 86.51 & 15.83 & 49.81 & 0.991 \\
$0^{\circ}$ & 6.40 & 70.30 & 13.89 & 46.86 & 0.980 \\
$30^{\circ}$ & 6.74 & 69.89 & 13.46 & 47.87 & 0.908 \\
$45^{\circ}$ & 5.03 & 37.51 & 8.36 & 41.94 & 0.990 \\
$90^{\circ}$ & 7.91 & 61.08 & 10.86 & 50.85 & 0.969 \\
\hline
\end{tabular}

108.27 MPa, while the corresponding peak strains are $10.79 \%$ and $9.62 \%$, respectively. The peak strength and peak strain of $p=8 \mathrm{MPa}$ are $4.37 \%$ and $10.88 \%$ smaller than those of $p=4 \mathrm{MPa}$, respectively. For $\sigma_{3}$ at $20 \mathrm{MPa}$, the corresponding peak strength values of $p=4 \mathrm{MPa}$ and $p=8 \mathrm{MPa}$ are 186.13 MPa and 152.12 MPa, and the corresponding peak 
TABLE 5: Parameters of the crack damage threshold corresponding to the linear $\mathrm{M}-\mathrm{C}$ criterion.

\begin{tabular}{lccccc}
\hline Joint angles & $M_{\mathrm{d}}$ & $N_{\mathrm{d}}(\mathrm{MPa})$ & $c_{\mathrm{d}}(\mathrm{MPa})$ & $\varphi_{\mathrm{d}}\left({ }^{\circ}\right)$ & $R^{2}$ \\
\hline Intact & 7.45 & 84.22 & 15.43 & 49.76 & 0.987 \\
$0^{\circ}$ & 5.50 & 56.16 & 11.97 & 43.81 & 0.990 \\
$30^{\circ}$ & 5.15 & 45.24 & 9.97 & 42.44 & 0.998 \\
$45^{\circ}$ & 3.05 & 38.01 & 10.88 & 30.41 & 0.935 \\
$90^{\circ}$ & 7.04 & 52.91 & 9.97 & 48.70 & 0.893 \\
\hline
\end{tabular}

Note: here, we use a subscript " $\mathrm{d}$ " for parameters corresponding to the crack damage threshold.

TABLE 6: Strength and deformation parameters of the specimens in triaxial compression drainage tests.

\begin{tabular}{|c|c|c|c|c|}
\hline Specimen label & $\sigma_{\mathrm{c}}(\mathrm{MPa})$ & $\varepsilon_{\mathrm{c}}\left(10^{-3}\right)$ & $E(\mathrm{GPa})$ & $E_{0}(\mathrm{GPa})$ \\
\hline SD- $0^{\circ}-10-4$ & 113.22 & 10.79 & 11.40 & 10.48 \\
\hline$S D-0^{\circ}-10-8$ & 108.27 & 9.62 & 12.31 & 11.66 \\
\hline$S D-0^{\circ}-20-4$ & 186.13 & 15.25 & 14.36 & 14.36 \\
\hline$S D-0^{\circ}-20-8$ & 152.12 & 12.34 & 13.95 & 10.62 \\
\hline SD $-45^{\circ}-10-4$ & 45.10 & 5.06 & 11.03 & 10.16 \\
\hline SD $-45^{\circ}-10-8$ & 21.22 & 2.74 & 9.04 & 8.50 \\
\hline SD $-45^{\circ}-20-4$ & 63.14 & 6.26 & 12.88 & 14.15 \\
\hline$S D-45^{\circ}-20-8$ & 33.99 & 4.20 & 11.84 & 13.55 \\
\hline SD- $90^{\circ}-10-4$ & 126.84 & 9.11 & 15.66 & 14.66 \\
\hline SD- $90^{\circ}-10-8$ & 131.37 & 13.60 & 13.64 & 10.67 \\
\hline SD-90 ${ }^{\circ}-20-4$ & 187.31 & 16.31 & 20.13 & 14.54 \\
\hline SD $-90^{\circ}-20-8$ & 185.23 & 15.68 & 16.61 & 14.68 \\
\hline
\end{tabular}

Note: $E_{0}$ is the modulus of deformation, namely, the slope of the connection line between the point of the half peak strength and the origin in the stressstrain curve.

strains are $15.25 \%$ and $12.34 \%$, respectively. The peak values are reduced by $18 \%$ and $8 \%$ compared with the previous stage of $\sigma_{3}$, and the peak strains are reduced by $19 \%$ and $7 \%$ compared with the previous stage, respectively.

As concluded in the previous section, a larger $\sigma_{3}$ leads to a larger $\sigma_{\mathrm{c}}$ and a larger $\varepsilon_{\mathrm{c}}$. However, compared with $\sigma_{3}$, the existence of $p$ may weaken $\sigma_{\mathrm{c}}$ and decrease $\varepsilon_{\mathrm{c}}$, and the effect of weakening due to $p$ is less obvious than the strengthening of $\sigma_{3}$. Moreover, for the previous tests under the condition of zero pore pressure, $\sigma_{\mathrm{c}}$ values of the $0^{\circ}$ jointed specimen under $\sigma_{3}$ at $10 \mathrm{MPa}$ and $20 \mathrm{MPa}$ are $148.19 \mathrm{MPa}$ and $207.29 \mathrm{MPa}$, respectively, while the corresponding peak strength values are reduced by $24 \%$ and $10 \%$, respectively, when $4 \mathrm{MPa}$ pore pressure is applied. It can be deduced that the effect of pore pressure is more obvious under the lower confining pressures. The reason for this phenomenon can be described as follows: when under high confining pressure, the mineral microstructure of the specimen is more compact, and hence, the seepage is more difficult to be triggered by the applied pore pressure. Besides, we find that the precompaction effect of the specimens can be more notable under a larger pore pressure condition because the larger pore pressure can weaken the cementation between the mineral components and make the mineral particles easier to be compacted, and

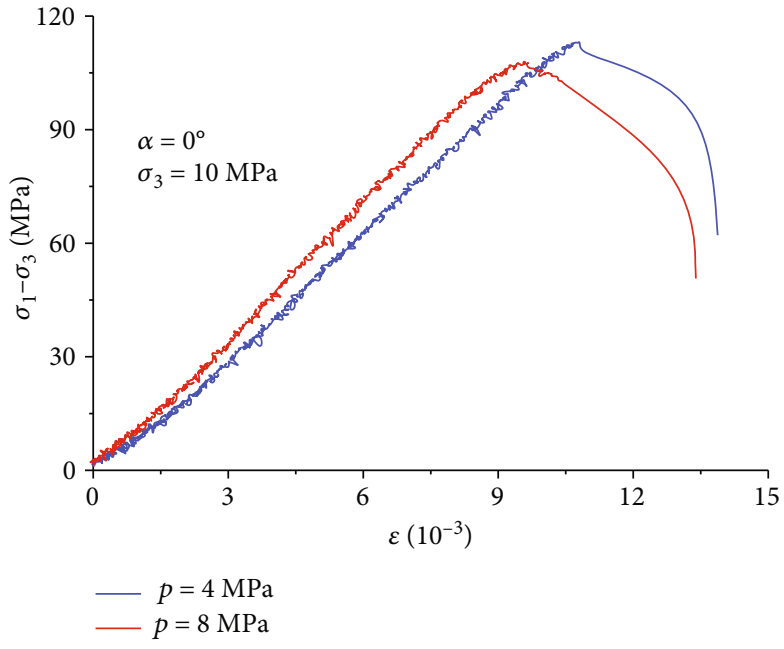

(a)

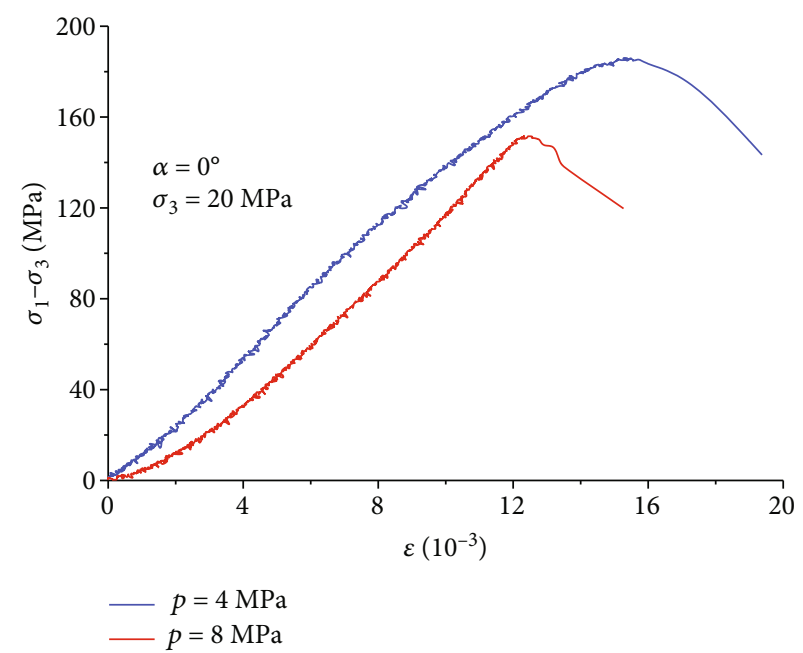

(b)

FIgURE 6: The typical stress-strain relationship of specimens with $\alpha=0^{\circ}$ : (a) $\sigma_{3}=10 \mathrm{MPa}$ and (b) $\sigma_{3}=20 \mathrm{MPa}$.

thus, the precompaction effect is more obvious. The specimen with a $90^{\circ}$ joint angle shows the most obvious compaction in this work.

4.2. Analysis of Deformation Characteristics. The relationship of the elastic modulus and the pore pressure is depicted in Figure 9. As the pore pressure increases, the elastic modulus shows a universal and gradual decrease. As a result of the larger pore pressure, it is easier to initiate softening of the mineral composition of the jointed rock and thus results in a larger amount of compression deformation. Therefore, a greater pore pressure leads to a greater compression deformation of the rock under the deviatoric loading, which finally reduces the elastic modulus. In addition, when the pore pressure increases, the difference in the elastic modulus among different confining pressures gradually decreases.

Figure 10 displays the relationship of the elastic modulus and the joint angle. The elastic modulus of the jointed specimen shows a V-shaped trend with the increase of the joint inclination angle, indicating that the existence of the joint 


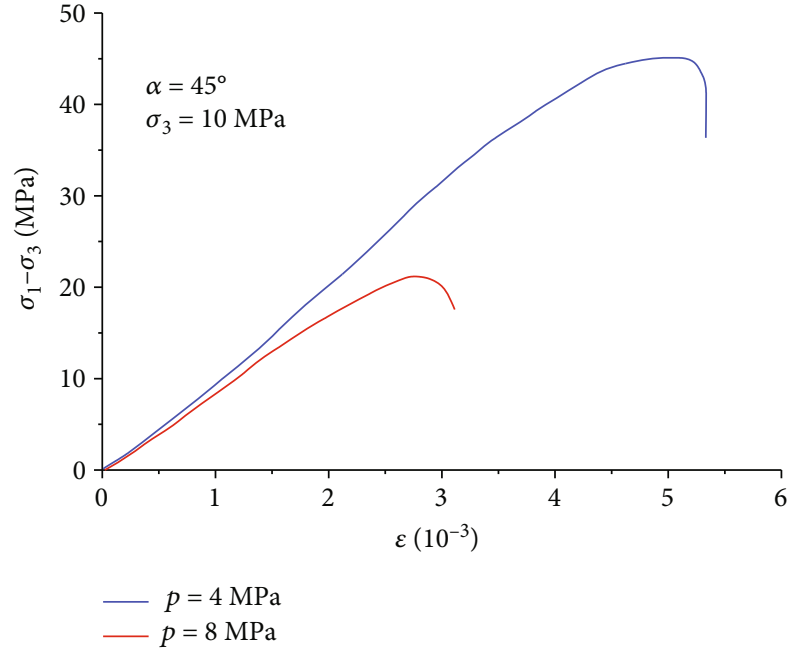

(a)

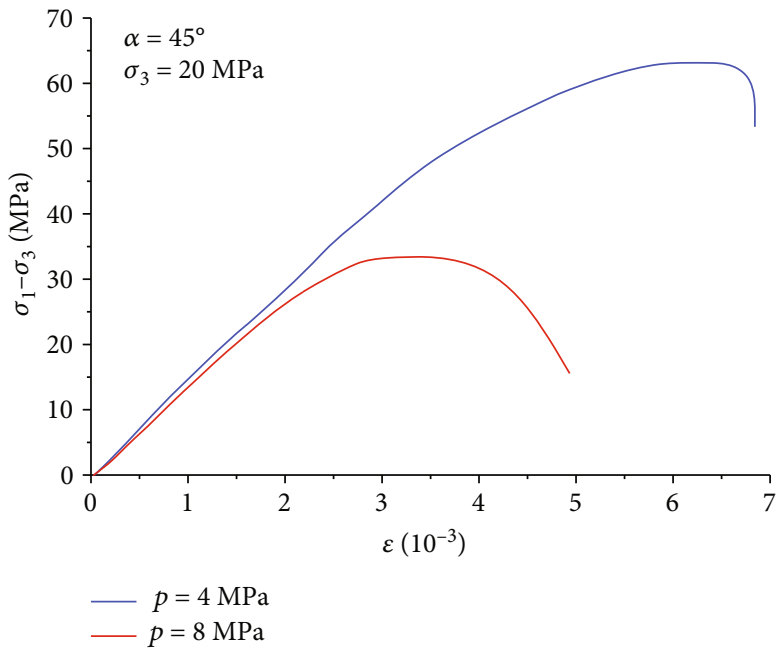

(b)

Figure 7: The typical stress-strain relationship of specimens with $\alpha=45^{\circ}$ : (a) $\sigma_{3}=10 \mathrm{MPa}$ and (b) $\sigma_{3}=20 \mathrm{MPa}$.

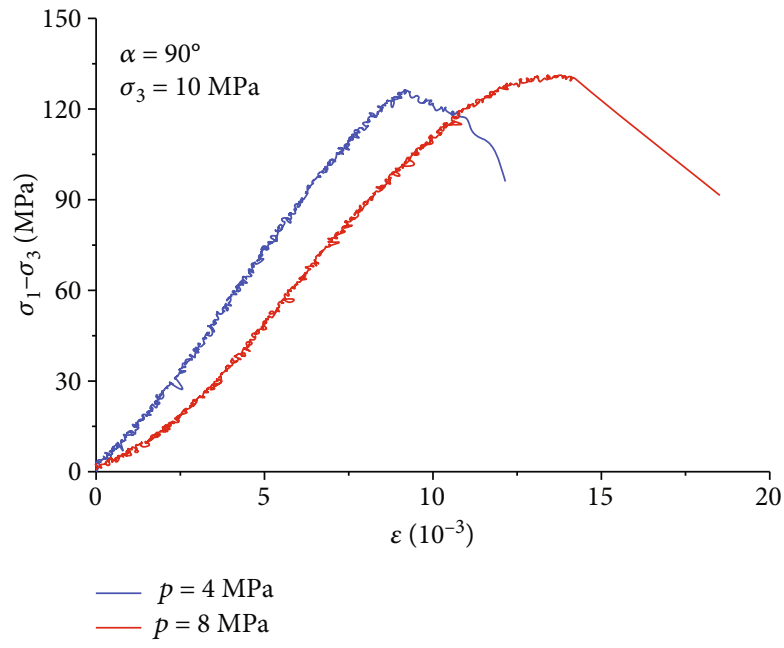

(a)

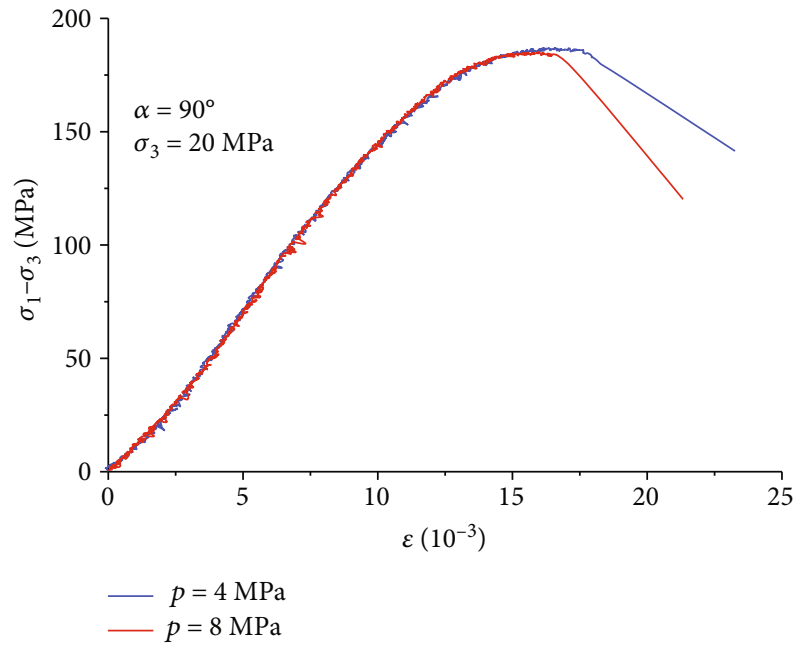

(b)

Figure 8: The typical stress-strain relationship of specimens with $\alpha=90^{\circ}$ : (a) $\sigma_{3}=10 \mathrm{MPa}$ and (b) $\sigma_{3}=20 \mathrm{MPa}$.

induces obvious anisotropy. The minimum values of the elastic modulus all appear at $45^{\circ}$ because of the susceptibility of sliding deformation along the $45^{\circ}$ joint surface under the action of loading, which leads to a small elastic modulus. Meanwhile, the elastic modulus of the $0^{\circ}$ jointed specimen is smaller than the elastic modulus of the $90^{\circ}$ jointed specimen; as a result of that, the $0^{\circ}$ jointed specimen may produce the compression deformation along the joint surface when the loading is applied, while the $90^{\circ}$ jointed specimen can only encounter the deformation of the rock itself. Due to the effect of pore pressure, the softening degree of the joint surface is greater than that of the rock mass, and thus, the axial deformation of the $0^{\circ}$ jointed specimen is greater than that of the $90^{\circ}$ jointed specimen.

4.3. The Effect of Joint Angles on Strength Characteristics When Considering the Pore Pressure. On the basis of the effect of seepage, the strength of the sandstone specimens will also show a roughly regular $\mathrm{V}$-shaped change with the increase of the joint inclination angle. Due to the various inclination angles, the seepage paths and seepage pressures are all different on the joint surface, which causes the differences of the strength weakening degree of the rock specimens. Controlling the confining pressure as the same value, the curves of the strength versus the joint inclination angle are shown in Figure 11.

For all the confining pressures and pore pressures, the peak strength of jointed specimens shows a $\mathrm{V}$-shaped change trend with the variation of joint angles. The minimum value is obtained at $45^{\circ}$, the larger values are obtained at $0^{\circ}$ and $90^{\circ}$, and the strength of $0^{\circ}$ and $90^{\circ}$ is almost the same. For instance, under the effect of a confining pressure of $20 \mathrm{MPa}$ and a pore pressure of $4 \mathrm{MPa}$, the peak values of the $0^{\circ}, 45^{\circ}$, and $90^{\circ}$ jointed specimens are $186.13 \mathrm{MPa}, 63.14 \mathrm{MPa}$, and 187.31 MPa, respectively. Under the action of pore pressure, the peak value of the $45^{\circ}$ jointed specimen is only about 


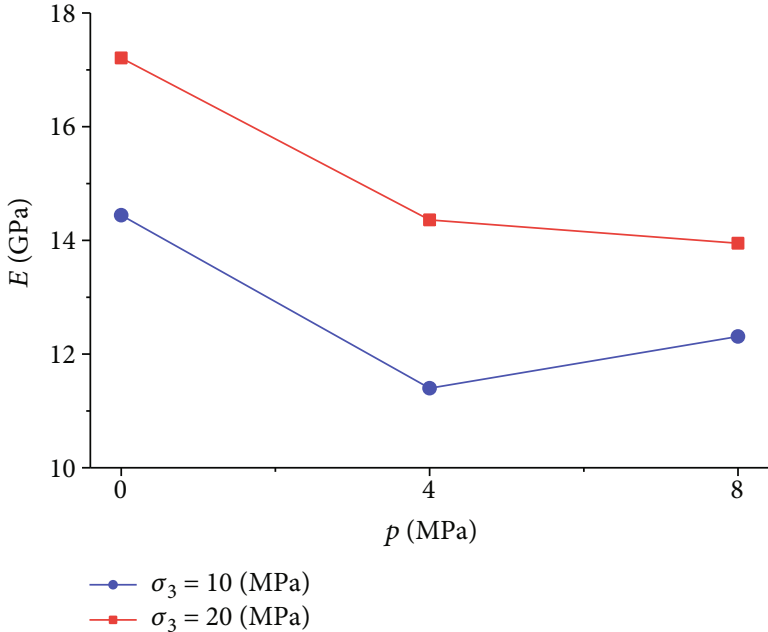

(a)

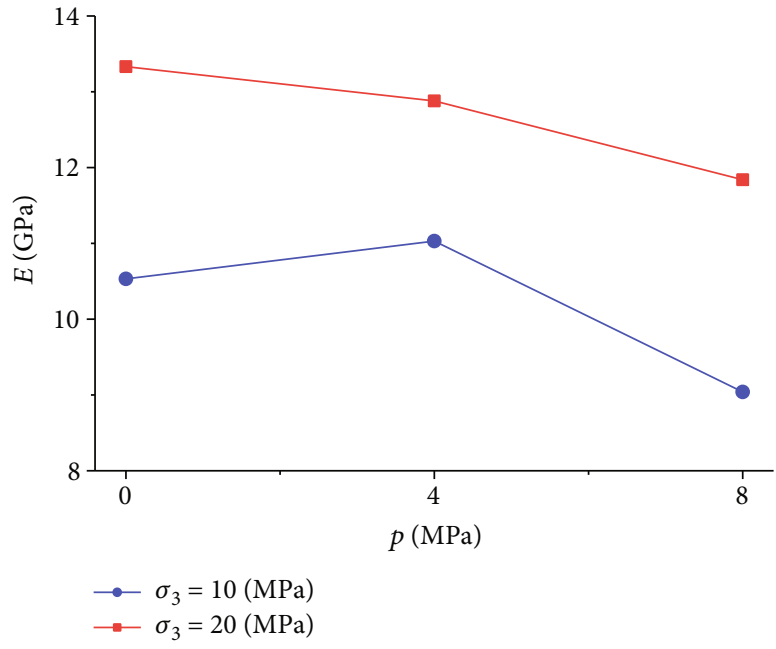

(b)

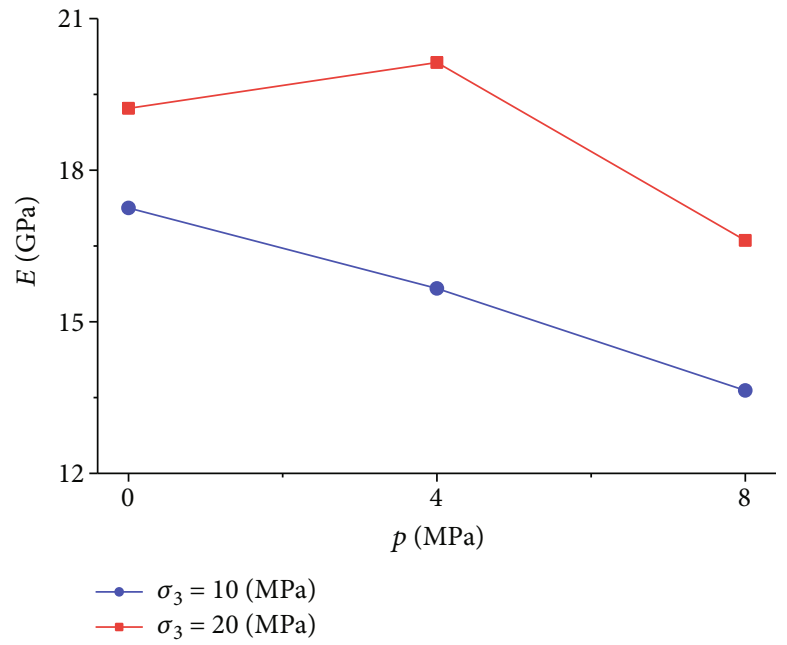

(c)

Figure 9: The relationship of the elastic modulus versus the pore pressure: (a) $\alpha=0^{\circ}$, (b) $\alpha=45^{\circ}$, and (c) $\alpha=90^{\circ}$.

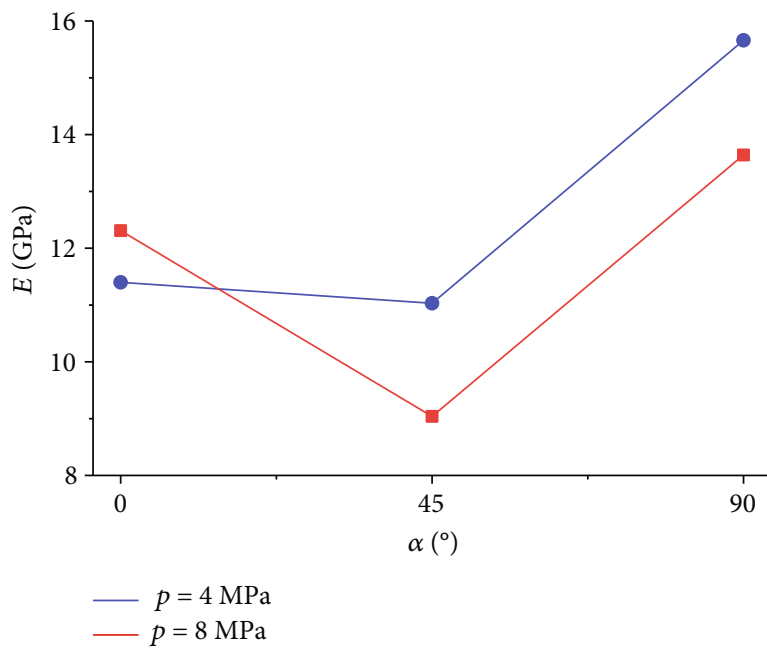

(a)

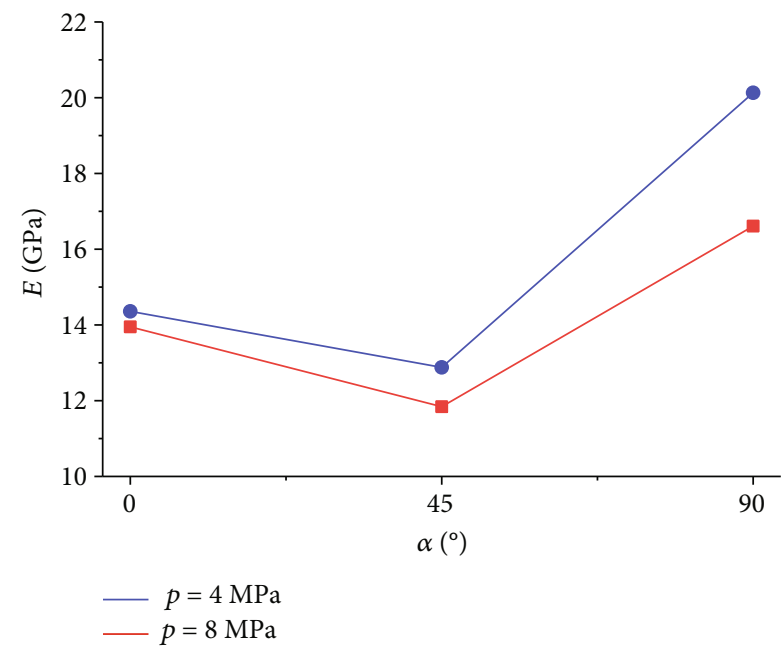

(b)

FIgURE 10: The relationship of the elastic modulus versus the joint angle: (a) $\sigma_{3}=10 \mathrm{MPa}$ and (b) $\sigma_{3}=20 \mathrm{MPa}$. 


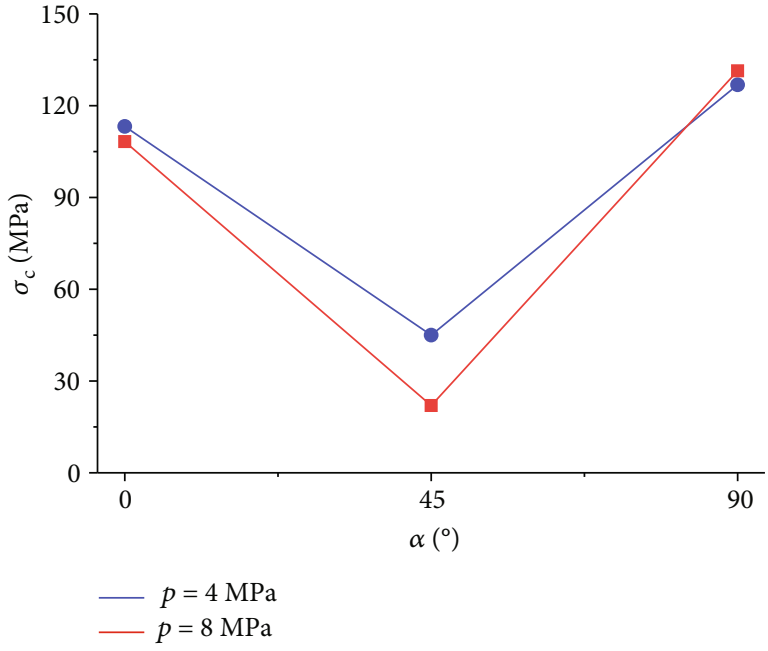

(a)

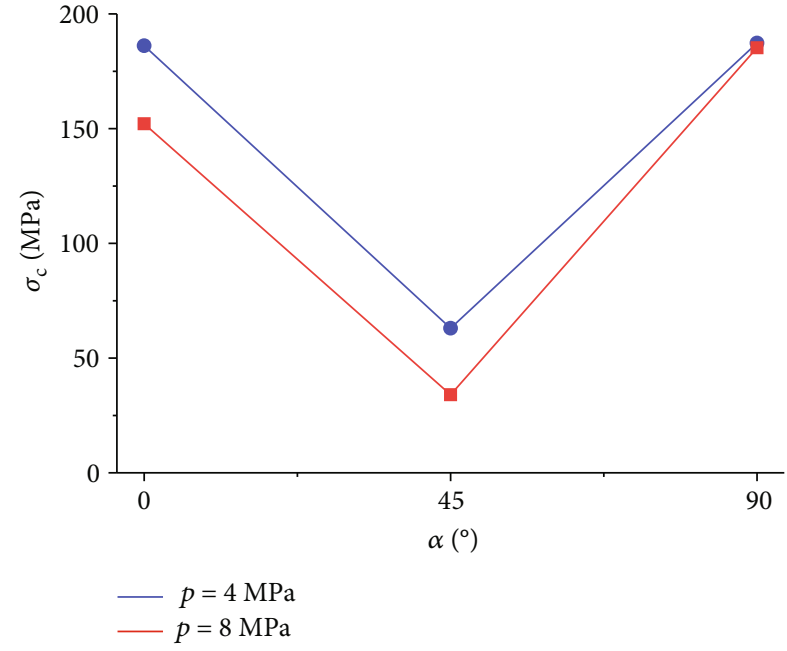

(b)

FIGURE 11: The relationship of the strength versus the joint angle: (a) $\sigma_{3}=10 \mathrm{MPa}$ and (b) $\sigma_{3}=20 \mathrm{MPa}$.
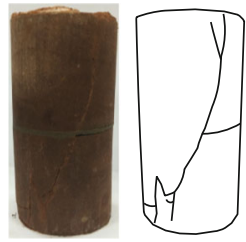

SD- $0^{\circ}-10-4$

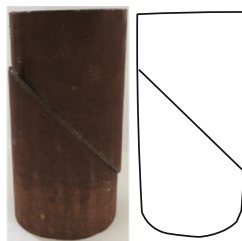

SD- $45^{\circ}-10-4$

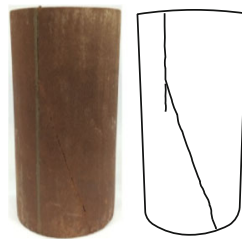

SD- $90^{\circ}-10-4$

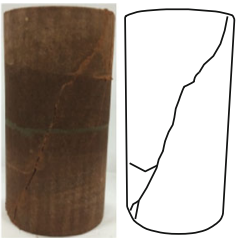

SD- $0^{\circ}-10-8$

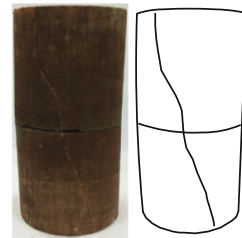

SD- $0^{\circ}-20-4$

(a)

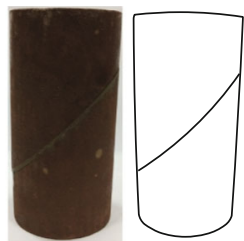

SD- $45^{\circ}-10-8$

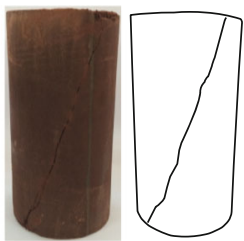

SD- $90^{\circ}-10-8$

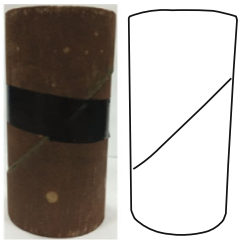

SD- $45^{\circ}-20-4$

(b)

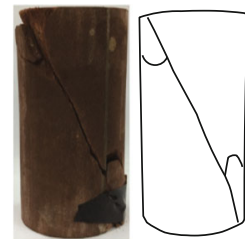

SD- $90^{\circ}-20-4$

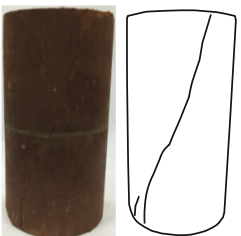

SD- $0^{\circ}-20-8$

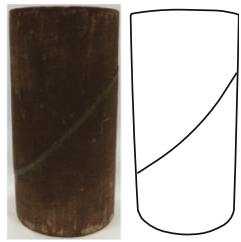

SD- $45^{\circ}-20-8$

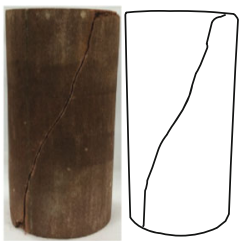

SD- $90^{\circ}-20-8$

(c)

Figure 12: The failure modes and their corresponding sketch maps of specimens: (a) $\alpha=0^{\circ}$, (b) $\alpha=45^{\circ}$, and (c) $\alpha=90^{\circ}$.

one-third of the peak value of the $0^{\circ}$ and $90^{\circ}$ jointed specimens, indicating that the oblique joint plane has a great influence on the strength of the rock mass when considering the pore pressure.

4.4. The Failure Mode Analysis. The failure modes and their corresponding sketch maps of specimens are demonstrated in Figure 12. All jointed specimens basically exhibited the shear failure mode, especially the $45^{\circ}$ jointed specimen. The $0^{\circ}$ joint sample not only has the shear failure surface through the rock but also has the failure surface along the joint surface. For zero pore pressure conditions, the $0^{\circ}$ joint sample is dominated by the shear failure surface through the rock, with slight cracks along the joint surface. When the pore pressure is applied, the $0^{\circ}$ joint surface will be penetrated by fractures, which has more obvious cracks characteristics than that under the condition of no pore pressure, indicating that the effect of the pore pressure can affect the failure mode of 
the $0^{\circ}$ jointed rocks to a certain extent. The water flow penetrates into the $0^{\circ}$ joint surface, which weakens the degree of cementation between the jointed material and the rock. After a penetrative fracture surface is formed under the deviatoric loading, the fracture surface will also occur along the $0^{\circ}$ joint surface. The $90^{\circ}$ jointed specimens mainly encounter the shear fracture surface which penetrates the rock, and the joint plane basically does not affect the failure mode of the rock.

Comparing the failure modes under different pore pressures, it is found that the pore pressure will affect the damage degree of the $0^{\circ}$ jointed specimen; i.e., the fracture surface along the joint plane can be more obvious. Unlikely, there is basically no effect of the pore pressure on the failure mode of the $45^{\circ}$ and $90^{\circ}$ jointed specimens, indicating that the pore pressure has relatively little effect on the shear failure modes of the rock. Comprehensively considering the failure modes of the specimens, four main failure modes under the effect of pore pressure are summarized as below: (1) the penetrating shear crack and the crack along the $0^{\circ}$ joint plane for the $0^{\circ}$ jointed specimens, $(2)$ the shear crack along the joint surface for the $45^{\circ}$ jointed specimens, (3) the penetrating shear crack of the whole rock for the $90^{\circ}$ jointed specimens, and (4) the shear cracks which first initiate along the shear surface and then penetrate the whole rock for the $90^{\circ}$ jointed specimens.

\section{Conclusions}

In this study, the conventional triaxial compression experiments and triaxial compression drainage tests for intact red sandstone and specimens with a single persistent joint are conducted. Based on the results, the stress-strain relationships, the deformation behavior, the strength parameters, and the failure characteristics are analyzed.

(1) According to results of conventional tests, the postpeak stress-strain curves of intact and jointed red sandstone all demonstrated the nonlinear stage, the elastic stage, the stable crack growth stage, and yielding stage, while the crack-induced volumetric strain versus axial strain curves of jointed specimens with different joint angles demonstrated a similar fourstage trend. Moreover, the relationship between the peak strength and the crack damage threshold fits the linear Mohr-Coulomb criterion well, and the mechanical parameters of specimens show a Ushaped trend with the raising of joint angle

(2) The results of triaxial compression drainage tests reveal that the elastic modulus of specimens gradually decreases with the rise of pore pressure and shows a V-shaped trend with the increase of the joint inclination angle. Similarly, the strength parameters show a V-shaped change trend for the enlargement of the pore pressure and the joint inclination angle. Finally, the crack modes in sandstone containing a single persistent joint under triaxial compression are further discussed
The conclusions of this study can be considered a reference for further studies with a wider range of rock and rock-like materials, joint geometries, and stress conditions.

\section{Data Availability}

The data used to support the findings of this study are available from the corresponding author upon request.

\section{Conflicts of Interest}

The authors declare no conflicts of interest.

\section{Acknowledgments}

This work was supported by the National Key Research and Development Program of China (No. 2017YFC1501100), National Natural Science Foundation of China (No. 12072102), Fundamental Research Funds for the Central Universities (No. B200203086), Postgraduate Research \& Practice Innovation Program of Jiangsu Province (No. KYCX20_0441), Six Talent Peaks Project in Jiangsu Province, and Program to Cultivate Middle-aged and Young Science Leaders of Colleges and Universities of Jiangsu Province, China. The authors also thank the Huzhou South Taihu innovation team for the support.

\section{References}

[1] R. H. C. Wong and K. T. Chau, "Crack coalescence in a rocklike material containing two cracks," International Journal of Rock Mechanics and Mining Sciences, vol. 35, no. 2, pp. 147164, 1998

[2] M. Prudencio and M. V. S. Jan, "Strength and failure modes of rock mass models with non-persistent joints," International Journal of Rock Mechanics and Mining Sciences, vol. 44, no. 6, pp. 890-902, 2007.

[3] C. H. Park and A. Bobet, "Crack coalescence in specimens with open and closed flaws: a comparison," International Journal of Rock Mechanics and Mining Sciences, vol. 46, no. 5, pp. 819829, 2009.

[4] S. Q. Yang and H. W. Jing, "Strength failure and crack coalescence behavior of brittle sandstone samples containing a single fissure under uniaxial compression," International Journal of Fracture, vol. 168, no. 2, pp. 227-250, 2011.

[5] Q. Wang, H. K. Gao, B. Jiang, S. C. Li, M. C. He, and Q. Qin, "In-situ test and bolt-grouting design evaluation method of underground engineering based on digital drilling," International Journal of Rock Mechanics and Mining Sciences, vol. 138, article 104575, 2021.

[6] Z. G. Tao, C. Zhu, M. C. He, and M. Karakus, "A physical modeling-based study on the control mechanisms of negative Poisson's ratio anchor cable on the stratified toppling deformation of anti-inclined slopes," International Journal of Rock Mechanics and Mining Sciences, vol. 138, article 104632, 2021.

[7] Q. Wang, Q. Qin, B. Jiang et al., "Mechanized construction of fabricated arches for large-diameter tunnels," Automation in Construction, vol. 124, article 103583, 2021.

[8] J. Rutqvist and O. Stephansson, "The role of hydromechanical coupling in fractured rock engineering," Hydrogeology Journal, vol. 11, no. 1, pp. 7-40, 2003. 
[9] A. Bobet and H. H. Einstein, "Fracture coalescence in rocktype materials under uniaxial and biaxial compression," International Journal of Rock Mechanics and Mining Sciences, vol. 35, no. 7, pp. 863-888, 1998.

[10] L. N. Y. Wong and H. H. Einstein, "Systematic evaluation of cracking behavior in specimens containing single flaws under uniaxial compression," International Journal of Rock Mechanics and Mining Sciences, vol. 46, no. 2, pp. 239-249, 2009.

[11] H. Lee and S. Jeon, "An experimental and numerical study of fracture coalescence in pre-cracked specimens under uniaxial compression," International Journal of Solids and Structures, vol. 48, no. 6, pp. 979-999, 2011.

[12] D. Huang, D. M. Gu, C. Yang, R. Q. Huang, and G. Y. Fu, "Investigation on mechanical behaviors of sandstone with two preexisting flaws under triaxial compression," Rock Mechanics and Rock Engineering, vol. 49, no. 2, pp. 375-399, 2016.

[13] S. Q. Yang and Y. H. Huang, "An experimental study on deformation and failure mechanical behavior of granite containing a single fissure under different confining pressures," Environmental Earth Sciences, vol. 76, no. 10, pp. 1-22, 2017.

[14] Y. Wang, W. K. Feng, R. L. Hu, and C. H. Li, "Fracture evolution and energy characteristics during marble failure under triaxial fatigue cyclic and confining pressure unloading (FCCPU) conditions," Rock Mechanics and Rock Engineering, vol. 54, no. 2, pp. 799-818, 2021.

[15] L. Y. Zhang, "Estimating the strength of jointed rock masses," Rock Mechanics and Rock Engineering, vol. 43, no. 4, pp. 391402, 2010 .

[16] A. Serrano, C. Olalla, and R. A. Galindo, "Micromechanical basis for shear strength of rock discontinuities," International Journal of Rock Mechanics and Mining Sciences, vol. 70, pp. 33-46, 2014.

[17] Y. Li, J. Oh, R. Mitra, and B. Hebblewhite, "Experimental studies on the mechanical behaviour of rock joints with various openings," Rock Mechanics and Rock Engineering, vol. 49, no. 3, pp. 837-853, 2016.

[18] Y. Li, J. Oh, and I. Canbulat, "A fractal model for the shear behaviour of large-scale opened rock joints," Rock Mechanics and Rock Engineering, vol. 50, no. 1, pp. 67-79, 2017.

[19] C. Zhu, M. C. He, M. Karakus, X. H. Zhang, and Z. G. Tao, "Numerical simulations of the failure process of anaclinal slope physical model and control mechanism of negative Poisson's ratio cable," Bulletin of Engineering Geology and the Environment, vol. 80, no. 4, pp. 3365-3380, 2021.

[20] W. J. Li and Q. Z. Zhu, "Fully meshfree numerical analysis of nonlocal damage in voxel-based material models from microtomography," International Journal of Solids and Structures, vol. 222-223, article 111021, 2021.

[21] Z. Chen, S. P. Narayan, Z. Yang, and S. S. Rahman, "An experimental investigation of hydraulic behaviour of fractures and joints in granitic rock," International Journal of Rock Mechanics and Mining Sciences, vol. 37, no. 7, pp. 10611071, 2000.

[22] Q. Yin, G. W. Ma, H. W. Jing et al., "Hydraulic properties of 3D rough-walled fractures during shearing: an experimental study," Journal of Hydrology, vol. 555, pp. 169-184, 2017.

[23] W. Wang, S. Y. Mei, Y. J. Cao, R. B. Wang, and Q. Z. Zhu, "Experimental study on property modification of jointed rocks subjected to chemical corrosion," European Journal of Environmental and Civil Engineering, pp. 1-12, 2020.
[24] C. G. Gong, W. Wang, J. F. Shao, R. B. Wang, and X. W. Feng, "Effect of water chemical corrosion on mechanical properties and failure modes of pre-fissured sandstone under uniaxial compression," Acta Geotechnica, vol. 16, no. 4, pp. 10831099, 2021.

[25] H. Shin and J. C. Santamarina, "An implicit joint-continuum model for the hydro-mechanical analysis of fractured rock masses," International Journal of Rock Mechanics and Mining Sciences, vol. 119, pp. 140-148, 2019.

[26] B. Li, R. Y. Bao, Y. Wang, R. C. Liu, and C. Zhao, "Permeability evolution of two-dimensional fracture networks during shear under constant normal stiffness boundary conditions," Rock Mechanics and Rock Engineering, vol. 54, no. 1, pp. 409-428, 2021.

[27] C. E. Fairhurst and J. A. Hudson, "Draft ISRM suggested method for the complete stress-strain curve for the intact rock in uniaxial compression," International Journal of Rock Mechanics and Mining Sciences, vol. 36, no. 3, pp. 279-289, 1999.

[28] Y. R. Li, D. Huang, and X. A. Li, "Strain rate dependency of coarse crystal marble under uniaxial compression: strength, deformation and strain energy," Rock Mechanics and Rock Engineering, vol. 47, no. 4, pp. 1153-1164, 2014. 